\title{
Supervisors, Transportation and Material Moving Workers
}

National Cancer Institute

\section{Source}

National Cancer Institute. Supervisors, Transportation and Material Moving Workers. NCI

Thesaurus. Code C122522.

Workers who directly supervise and coordinate activities of aircraft cargo handlers;

helpers, laborers, and hand material movers; and transportation and material-moving

machine and vehicle operators. 